\title{
Efecto de extractos orgánicos naturales sobre la micropropagación de Vanilla planifolia Jacks. ex Andrews (Orchidaceae)
}

\author{
Effect of natural extracts on the micropropagation of Vanilla planifolia Jacks. \\ ex Andrews (Orchidaceae)
}

\begin{abstract}
Candy Carranza-Álvarez ${ }^{*}$, Karina Lizbeth Trinidad-García², Humberto Reyes-Hernández ${ }^{3}$, Luis Jesús Castillo-Pérez², Javier Fortanelli-Martínez ${ }^{4}$

Facultad de Estudios Profesionales Zona Huasteca, Universidad Autónoma de San Luis Potosí. Ciudad Valles, S.L.P., México. 2 Programas Multidisciplinarios de Posgrado en Ciencias Ambientales, Universidad Autónoma de San Luis Potosí. San Luis Potosí, S.L.P., México.

Facultad de Ciencias Sociales y Humanidades, Universidad Autónoma de San Luis Potosí. San Luis Potosí, S.L.P., México.

4 Instituto de Investigaciones de Zonas Desérticas, Universidad Autónoma de San Luis Potosí. San Luis Potosí, S.L.P., México.
\end{abstract}

\section{RESUMEN}

Vanilla planifolia Jacks. ex Andrews es una orquídea de gran importancia económica, que presenta problemas de sobreexplotación y amenaza en su hábitat original. Por lo cual, el objetivo de esta investigación fue establecer un protocolo de micropropagación in vitro evaluando el efecto diferentes extractos orgánicos. El cultivo in vitro se inició a través de la germinación de semillas que dieron lugar a la formación de protocormos. Los protocormos se cultivaron en medios MS suplementados con extractos naturales: MPL (plátano), MPI (piña), MCO (agua de coco) y medio control, para promover la morfogénesis. Posteriormente, para inducir la rizogénesis de los brotes y la aclimatación, se utilizaron tratamientos con auxinas (AIA y AIB). Los resultados mostraron que la germinación inició a los 60 días de cultivo in vitro, y que la adición de los extractos orgánicos promovió la diferenciación de los brotes, resultando más eficiente el tratamiento MPI. Además, la adición de $0.5 \mathrm{mg} \mathrm{L}^{-1}$ de AIA promovió el enraizamiento y la pre aclimatación in vitro. Estos resultados sugieren que los extractos orgánicos promueven la morfogénesis de vainilla, sin necesidad de emplear reguladores de crecimiento sintéticos en las primeras etapas de la micropropagación in vitro.

Palabras-clave: Vainilla, micropropagación, extractos naturales.

\section{ABSTRACT}

Vanilla planifolia Jacks. ex Andrews is an orchid of great economic importance, which faces problems due to overexploitation and threat of its original habitat. Therefore, the aim of the present investigation was to establish an in vitro micropropagation protocol evaluating the effect of different organic extracts.

The first stage of the in vitro culture was the seeds germination leading to the formation of protocorms. The protocorms were grown in MS media supplemented with natural extracts: MPL (banana), MPI (pineapple), MCO (coconut water) and control medium, to promote morphogenesis. Subsequently, to induce shoots rhizogenesis and acclimatization, auxin treatments (AIA and AIB) were used. The results

\footnotetext{
*Autor para correspondencia: Candy Carranza-Álvarez

Correo electrónico: candy.carranza@uaslp.mx

Recibido: 13 de agosto de 2020
}

Aceptado: 22 de octubre de 2020 showed that in vitro germination began at 60 days, and that the addition of organic extracts promoted the differentiation of the shoots, resulting the MPI treatment more efficient. Furthermore, the addition of $0.5 \mathrm{mg} \mathrm{L}^{-1}$ of IAA promoted vitroplants rooting and pre-acclimatization. These results suggest that organic extracts promote the vanilla morphogenesis, without synthetic growth regulators in the early stages of in vitro micropropagation.

Keyword: vanilla, micropropagation, natural extracts.

\section{INTRODUCCIÓN}

Vanilla planifolia Jacks. ex Andrews es una planta hemiepífita o terrestre de la familia Orchidaceae, de clima cálido, que se desarrolla en condiciones de luz y sombra bajo temperaturas de entre 20 y $30^{\circ} \mathrm{C}$, y para su desarrollo necesita un sostén (otra planta o un árbol, la cual es llamada tutor) (Hernández-Hernández, 2011). Su ciclo de vida inicia a los dos años de crecimiento vegetativo, y durante el tercer año inicia la producción de las vainas de donde se obtiene la esencia comercial mundialmente conocida como vainilla (Kelso-Bucio et al., 2012).

Esta planta posee su centro de origen en México, siendo los principales productores de vainilla los estados de Veracruz, Oaxaca, Puebla y San Luis Potosí (Luna-Guevara et al., 2016). En San Luis Potosí, los municipios con mayor producción de vainilla son Axtla de Terrazas, Tamazunchale, Aquismón, Matlapa, Coxcatlán, Huehuetlán y Xilitla, situados en la Huasteca Potosina, los cuales han desarrollado sistemas de cultivo y producción de vainilla tradicionales (VargasHernández y Gámez-Vázquez, 2014; Reyes-Hernández et al., 2018).

Actualmente, la vainilla se considera una especie amenazada (NOM-059-SEMARNAT-2010), debido a la sobreexplotación, lo que ha reducido las poblaciones silvestres y mermado la diversidad genética (Soto-Arenas 1999; SAGARPA, 2010). Además, la propagación de la vainilla se encuentra limitada por problemas naturales como la reducida viabilidad de las semillas y las bajas tasas de germinación (Soto-Arenas 2006; Torres-González et al., 2011). Por esta razón, se propaga 
asexualmente, sin embargo, este método no garantiza la calidad de las nuevas plantaciones, y se limita a un pequeño número de esquejes por planta donante. Esta problemática afecta principalmente a los productores que dependen de este cultivo tradicional, por lo que es importante establecer alternativas que contribuyan no sólo al rescate de la especie vegetal, sino también a crear metodologías de propagación que garanticen la disponibilidad de material para solucionar las necesidades de los distintos sectores de interés (FloresCastaños et al., 2017).

En este sentido, el cultivo de tejidos vegetales (CTV) es una herramienta biotecnológica útil para producir una gran cantidad de plantas en un tiempo relativamente corto, con calidad y rendimiento uniforme, con independencia de las variaciones geográficas, estacionales y ambientales, y sin uso de pesticidas y/o herbicidas (Rao y Ravishankar, 2002; Debnath, 2009; Espinosa-Leal et al., 2018). En la actualidad, mediante el CTV es posible micropropagar especies con problemas de conservación como las orquídeas (GaudencioSedano et al., 2015). La micropropagación de orquídeas es una herramienta del CTV indispensable para la propagación in vitro de semillas y clones, especialmente con fines comerciales (Thammasiri et al., 2020).

Por lo anterior, el objetivo de la presente investigación fue establecer un protocolo de regeneración in vitro de $\mathrm{V}$. planifolia a través del uso de extractos orgánicos naturales (agua de coco, jugo de piña y pulpa de plátano), para garantizar la producción de plántulas de vainilla de manera orgánica.

\section{MATERIALES Y MÉTODOS \\ Material vegetal}

Los especímenes de $V$. planifolia fueron recolectados en la comunidad de Cuichapa, Matlapa, San Luis Potosí, México (coordenadas: 21019'4.00" LN y 98 $49^{\prime 3} 33.99^{\prime \prime}$ LW), y proporcionados por el Centro de Acopio y beneficiado de vainilla, palmilla, café, piloncillo y derivados GANCA, S.P.R de R.L. (Grupo Antonio Calderón). Las plantas fueron colocadas en maceta con tierra de jardín, y adaptadas en condiciones de invernadero $\left(25^{\circ} \mathrm{C}\right.$ y $70 \%$ de humedad). La polinización de estas plantas se realizó de forma manual siguiendo la metodología establecida por Menchaca-García (2011). Para inducir la germinación de las semillas se utilizó el medio basal con vitaminas MS (Murashige y Skoog, 1962; Phyto Technology Laboratories, LLC., Lenexa, Kansas) suplementado con $30 \mathrm{~g} \mathrm{~L}^{-1}$ de sacarosa, $5.0 \mathrm{~g} \mathrm{~L}^{-1}$ de carbón activado (Karal S.A. de C.V, León, México) y $8 \mathrm{~g} \mathrm{~L}^{-1}$ de agar (Phyto Technology Laboratories, LLC., Lenexa, Kansas, Shawnee Mission, Kansas; Plant Tissue Culture grade).

El pH de los medios de cultivo se ajustó a 5.7 y se esterilizaron a $120^{\circ} \mathrm{C}$ por 20 minutos $\left(1.37 \times 10^{5} \mathrm{~Pa}\right)$. Los cultivos se mantuvieron a $25^{\circ} \mathrm{C}$ con un fotoperiodo de 16 horas de luz a $45 \mu \mathrm{mol} \mathrm{m} \mathrm{m}^{-2}$ y 8 horas de oscuridad, la luz fue suministrada con lámparas fluorescentes blanco frío (Phillips, Saltillo, México).

\section{Volumen XXIII, Número 1}

\section{Asepsia de la cápsula y protocolo de germinación}

En el presente trabajo, la micropropagación in vitro se realizó utilizando semillas inmaduras de $V$. planifolia provenientes de frutos de $15 \mathrm{~cm}$ de longitud, obtenidos por polinización artificial en condiciones de cultivo de malla-sombra.

Las cápsulas de $V$. planifolia antes de la dehiscencia fueron desinfectadas de forma superficial con jabón antibacterial al $40 \%$ por $20 \mathrm{~min}, \mathrm{AgNO}_{3}$ al $10 \%$ por 15 minutos, etanol al $70 \%$ por $2 \mathrm{~min}$, con hipoclorito de sodio al $10 \%$ y tres gotas de Tween ${ }^{\oplus} 80$ en $100 \mathrm{~mL}$ de agua durante $10 \mathrm{~min}$. Finalmente, se lavaron tres veces con agua destilada estéril. Las semillas fueron cultivadas para germinar en medio MS basal adicionado con $5 \%(\mathrm{p} / \mathrm{v})$ de carbón activado (Karal S.A. de C.V, León, México) sin reguladores de crecimiento vegetal.

Los medios de cultivo con las semillas inoculadas se mantuvieron en oscuridad por cuatro semanas dentro del cuarto de cultivo del Laboratorio de Investigación en Ciencias Ambientales de la U.A.S.L.P., a una temperatura de $25^{\circ} \mathrm{C}$, y posteriormente otras cuatro semanas con un fotoperiodo de $16 \mathrm{~h}$ de luz y $8 \mathrm{~h}$ de oscuridad, la luz fue suministrada con lámparas fluorescentes blanco frío (Phillips, Saltillo, México).

\section{Inducción de brotes a partir de protocormos}

Para inducir el desarrollo de brotes, se utilizaron protocormos de 16 semanas de edad. Las vitroplantas se cultivaron en medio MS con $15 \mathrm{~g} \mathrm{~L}^{-1}$ de sacarosa, $0.5 \%$ de carbón activado, $8 \mathrm{~g} \mathrm{~L}^{-1}$ de agar phytagel (Phyto Technology, Shawnee Mission, KS; Plant Tissue Culture grade), y se suplementaron con extractos orgánicos naturales, resultando las siguientes combinaciones: medio MS sin extractos (control), medio MS con $10 \mathrm{~g} \mathrm{~L}^{-1}$ de extracto de piña (MPI), medio MS con $10 \mathrm{~g} \mathrm{~L}^{-1}$ de extracto de plátano (MPL) y medio MS con 30 $\mathrm{mL} \mathrm{L}^{-1}$ de agua de coco (MCO). Los sustratos naturales utilizados fueron obtenidos de Phyto Technology Laboratories.

$\mathrm{El} \mathrm{pH}$ de los medios se ajustó a 5.7 con $\mathrm{NaOH} 1 \mathrm{~N}$ y/o $\mathrm{HCl} 1 \mathrm{~N}$. Los protocormos se sembraron en estos medios de cultivo durante 60 días, y se mantuvieron a $25^{\circ} \mathrm{C}$ con un fotoperiodo de $16 \mathrm{~h}$ de luz a $45 \mu \mathrm{mol} \mathrm{m} \mathrm{m}^{-2} \mathrm{~s}^{-1}$ y 8 horas de oscuridad, la luz fue suministrada con lámparas fluorescentes blanco frío (Phillips, Saltillo, México). Se realizaron evaluaciones mensuales del número y altura de los brotes nuevos producidos.

\section{Enraizamiento de los brotes}

Los brotes de $V$. planifolia mayores a $4 \mathrm{~cm}$ se retiraron del medio de cultivo, se enjuagaron en agua destilada estéril para eliminar por completo los restos del medio de cultivo, y se sembraron en recipientes de vidrio de $100 \mathrm{~mL}$ con diferentes tratamientos para inducir la formación de la raíz. Los tratamientos fueron los siguientes: i) medio MS basal (Tratamiento Control); ii) medio MS con $10 \mathrm{~g} \mathrm{~L}^{-1}$ de extracto de piña más $1 \mathrm{mg} \mathrm{L}^{-1}$ de 6-bencilaminopurina (BAP) más $0.5 \mathrm{mg}$ $\mathrm{L}^{-1}$ de AIA (Tratamiento $0.5 \mathrm{AIA}$ ) y iii) medio MS con $10 \mathrm{~g} \mathrm{~L}^{-1}$ de extracto de piña más $1 \mathrm{mg} \mathrm{L}^{-1}$ 6-bencilaminopurina (BAP) más $1.0 \mathrm{mg} \mathrm{L}^{-1}$ de AIA (Tratamiento $1.0 \mathrm{AIA}$ ). Los diferentes tratamientos se preservaron en condiciones del cuarto de 
cultivo, y se registró el número y la longitud de raíces, y el porcentaje de oxidación durante 60 días.

\section{Preaclimatación in vitro}

Las plántulas de $V$. planifolia mayores a $6 \mathrm{~cm}$ y con mayor número y longitud de raíces se retiraron de los medios de cultivo, se enjuagaron en agua destilada estéril, y se sometieron a un proceso de pre aclimatación in vitro, para lo cual se sembraron en frascos de vidrio con capacidad de $500 \mathrm{~mL}$ con diferentes tratamientos: i) suelo orgánica estéril (control), ii) suelo orgánico estéril con $1.0 \mathrm{mg} \mathrm{L}^{-1}$ de AIA (Tratamiento TAIA1.0) y iii) suelo orgánico estéril con $2.0 \mathrm{mg} \mathrm{L}^{-1}$ de AIA (Tratamiento TAIA2.0). Las vitroplantas se preservaron en condiciones del cuarto de cultivo, y se registró la longitud, el número de hojas, el porcentaje de oxidación y el porcentaje de contaminación semanalmente durante 41 días de cultivo.

\section{Diseño experimental y análisis estadístico}

Se utilizó un diseño completamente al azar para comparar los tratamientos. En cada tratamiento evaluado se establecieron 10 frascos como repetición, en cada frasco se sembraron cinco vitroplantas, para un total de 50 vitroplantas por tratamiento. Se utilizó un diseño experimental completamente al azar. Su desarrollo en cada tratamiento fue evaluado mensualmente. Se registraron tres variables en la primera etapa de inducción de brotes (número de brotes, altura de los brotes, formación de yemas), en la segunda etapa denominada enraizamiento se registraron dos variables (número de raíces y longitud de raíces), y en la última etapa denominada pre aclimatación se evaluaron dos variables adicionales (altura de las plantas y formación de hojas nuevas).

Todos los datos fueron registrados como media \pm error estándar de la media (SEM). Posteriormente, para cada variable se realizó un análisis de varianza (ANOVA) de una vía tipo modelo lineal general (MLG), verificando previamente los supuestos de normalidad (prueba de KolmogorovSimirnov) y homogeneidad de varianzas (prueba de Levene). Adicionalmente, se utilizó la prueba de Tukey $(p<0.05)$ para comparar las medias entre los diferentes tratamientos. Los análisis estadísticos se realizaron con el programa Statistic para Windows, versión 8.0.

\section{RESULTADOS}

\section{Germinación de las semillas}

La germinación asimbiótica de las semillas de V. planifolia se logró a los 90 días de cultivo in vitro, en donde se observó un porcentaje de germinación mayor al $90 \%$ (Figura 1). La germinación se indujo al colocar las semillas en la oscuridad durante los primeros 30 días. Posterior a los 60 días de cultivo, se observó un hinchamiento y cambio de coloración de las semillas, que culminó con la formación de protocormos (PLB's: Protocorm Like Bodies) a los 90 días (Figura 2A).

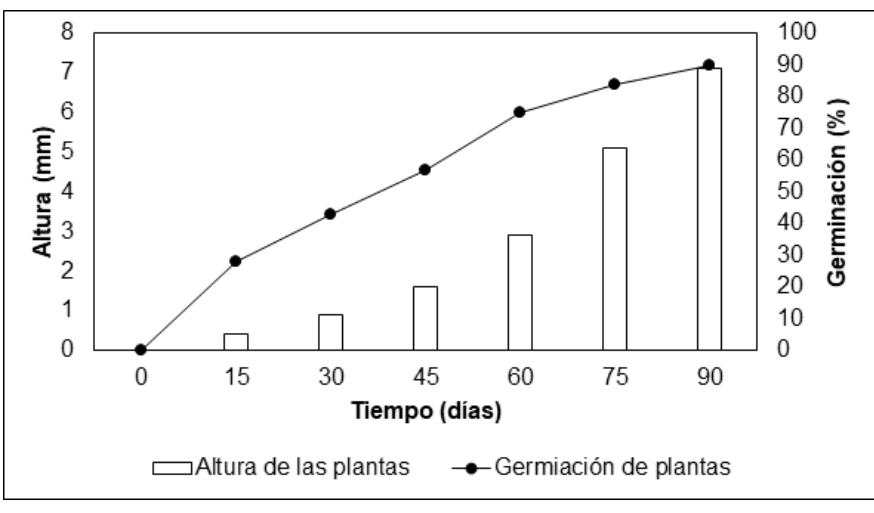

Figura 1. Germinación de semillas y crecimiento de plántulas de $V$. planifolia. Las semillas germinaron en medio MS basal adicionado con $1 \%(\mathrm{p} / \mathrm{v})$ de carbón activado.

Figure 1. Seed germination and seedling growth of $V$. planifolia. Seeds germinated in basal MS medium added with $1 \%(\mathrm{w} / \mathrm{v})$ of activated charcoal.
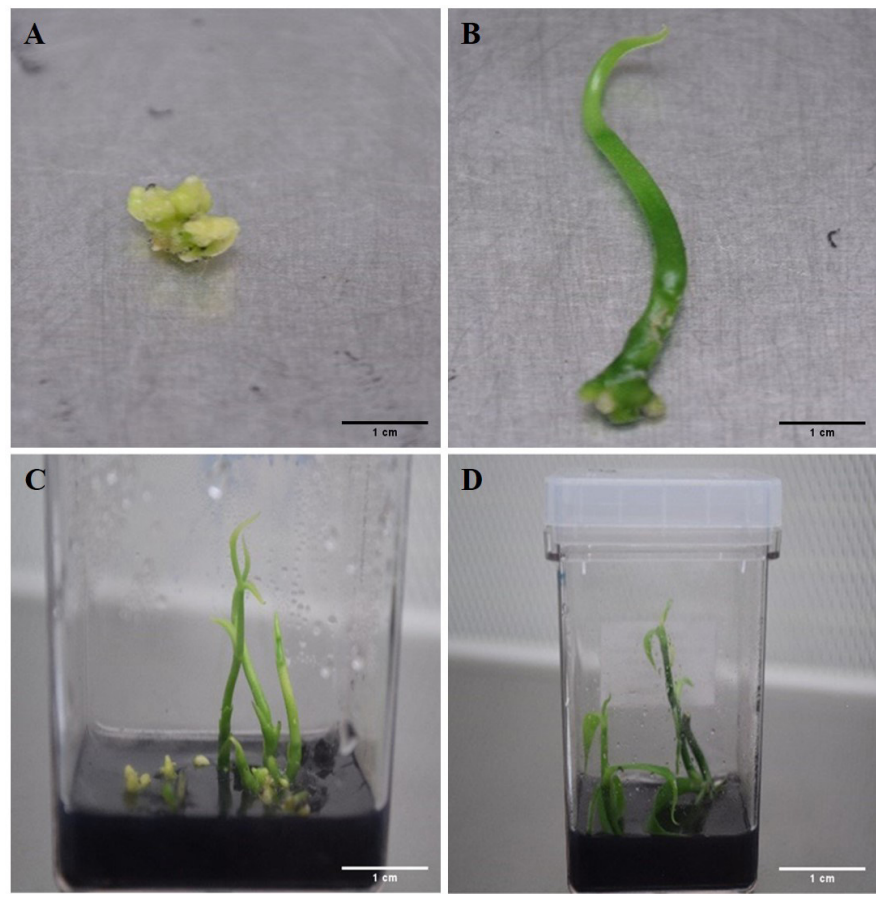

Figura 2. Desarrollo morfológico de V. planifolia. (A) Protocormo; (B) Formación de brote a partir de protocormo; (C) Aparición de yemas en los brotes; (D), Formación de raíces y hojas. Barra $1 \mathrm{~cm}$.

Figure 2. Morphological development of V. planifolia. (A) Protocorm; (B) Outbreak formation from protocorm; (C) Bud appearance; (D), Roots and leaves formation. Bar $1 \mathrm{~cm}$. 


\section{Efecto de sustratos naturales sobre la formación de bro- tes a partir de protocormos}

Una vez formados los protocormos de V. planifolia, se observó el crecimiento de pequeños brotes apicales de color verde oscuro a los 28 días de cultivo, como resultado del cultivo de éstos en los tratamientos con diferentes sustratos orgánicos. El porcentaje de respuesta fue dependiente del tratamiento empleado. Se observó un $100 \%, 93.4 \%, 33.5 \%$ y $33 \%$ de respuesta en los MCO, MPI, MPL y control, respectivamente.

La formación de brotes definidos se presentó hasta los 120 días de cultivo, después de dos subcultivos realizados cada 60 días (Figura 2B). Se consideraron brotes definidos, aquellos que presentaron al menos una yema con dos hojas. El tratamiento suplementado con extracto de piña (MPI) fue en donde se observó la mayor producción de brotes $(5.7 \pm$ 3.5), resultado significativamente diferente con respecto al control. El tratamiento MCO produjo $4.6 \pm 2.7$ brotes, seguido del control ( $4.6 \pm 3.3$ brotes) y el tratamiento con extracto de plátano (MPL) el cual produjo $4.2 \pm 2.7$ brotes. Los tratamientos MCO y MPL no mostraron diferencia estadística significativa, respecto al control (Figura $3 \mathrm{~A}$ ).

En relación con la altura de los brotes, se observó un mayor incremento en los tratamientos MPI y MCO, cuyas alturas oscilaron entre $36.9 \pm 17.3$ y $35.1 \pm 18.8 \mathrm{~mm}$ respectivamente, resultados estadísticamente significativos respecto al
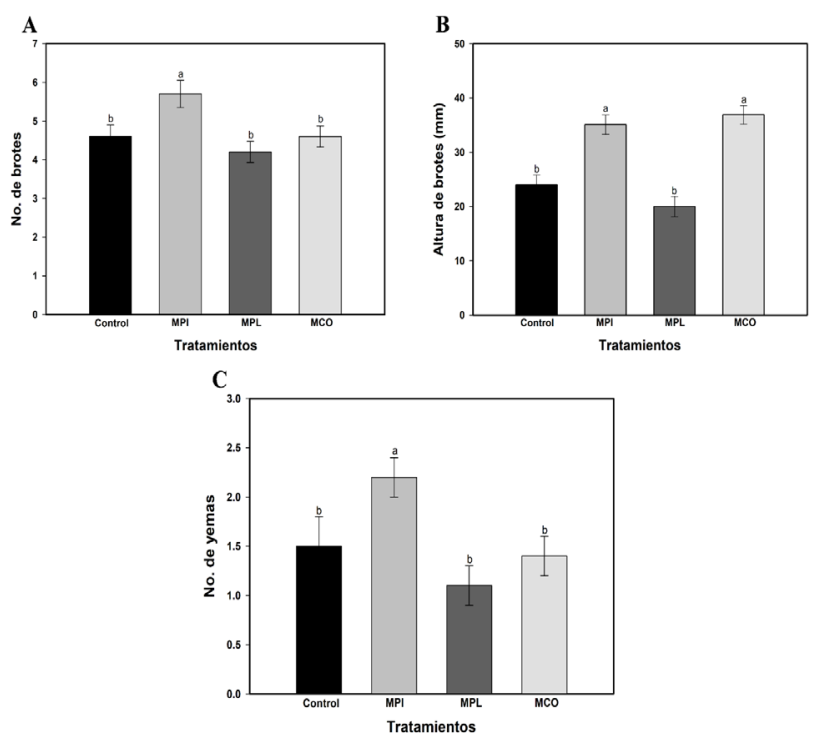

Figura 3. Respuesta de las vitroplantas de V. planifolia a la adición de EO. (A) Producción media del número de brotes; (B) Altura media de los brotes producidos; (C) Producción media del número de yemas. Las barras de error representan el error estándar de las concentraciones $(n=50)$. Las medias con diferentes letras muestran diferencias significativas $(p<0.05)$ de acuerdo con el análisis de Tukey.

Extractos orgánicos: MPI (piña); MPL (plátano); MCO (agua de coco). Figure 3. V. planifolia vitroplants response to OE addition. (A) Average production of shoots; (B) Average height of shoots produced; (C) Average production of buds. Error bars represent the standard error of the concentrations $(n=50)$. Means with different letters show significant differences ( $p$ $<0.05$ ) according to Tukey's analysis.

Organic extracts: MPI (pineapple); MPL (banana); MCO (coconut water). control $(p<0.05)$. Los brotes desarrollados en el tratamiento control y el MPL alcanzaron una altura de $20 \pm 19 \mathrm{~mm}$ y $24 \pm$ $18.8 \mathrm{~mm}$, respectivamente (Figura $3 \mathrm{~B}$ ).

A los 120 días de cultivo, se presentó la formación de yemas en los brotes. El tratamiento MPI desarrolló $2.2 \pm 0.5$ yemas, lo cual fue estadísticamente significativo $(p<0.05)$ respecto al control, el cual desarrollo sólo $1.5 \pm 0.3$ yemas. Los tratamientos MCO y MPL registraron el desarrollo de 1.5 \pm 0.2 y $1.0 \pm 0.3$ yemas por explante, sin mostrar diferencias estadísticamente significativas con respecto al control (Figura 3C).

\section{Efecto de la concentración de ácido indol acético (AIA) sobre la rizogénesis de los brotes}

Para el proceso de rizogénesis de los brotes de $V$. planifolia, en los tratamientos adicionados con AIA se evaluaron dos variables: 1) la producción del número de raíces y 2) la longitud que alcanzaron las raíces desarrolladas. Los resultados mostraron que el máximo porcentaje de brotes con raíces se obtuvo a los 66 días de cultivo en el tratamiento $0.5 \mathrm{AlA}$ el cual presentó un $61 \%$ de respuesta, mientras que el control presentó un $41 \%$ y un $17 \%$ en el tratamiento 1.0 AIA. La mayor producción del número de raíces se obtuvo en el tratamiento adicionado con $0.5 \mathrm{mg} \mathrm{L}^{-1}$ de AIA, en el cual se desarrollaron $13.0 \pm 0.9$ raíces por brote. Los tratamientos control y el adicionado con $1.0 \mathrm{mg} \mathrm{L}^{-1}$ de AIA mostraron los valores más bajos para la producción de raíces $(5.0 \pm 1.0$ y $3.0 \pm 0.4$ raíces por brote, respectivamente) sin diferencias significativas entre ellos ( $p>0.05)$.

Los resultados observados en el tratamiento 0.5 AIA fueron estadísticamente significativos $(p<0.05)$ respecto a los dos tratamientos restantes (Figura 4A). La longitud de las raíces también fue mayor en el tratamiento adicionado con $0.5 \mathrm{mg} \mathrm{L}^{-1}$ de AIA, en el cual las vitroplantas desarrollaron
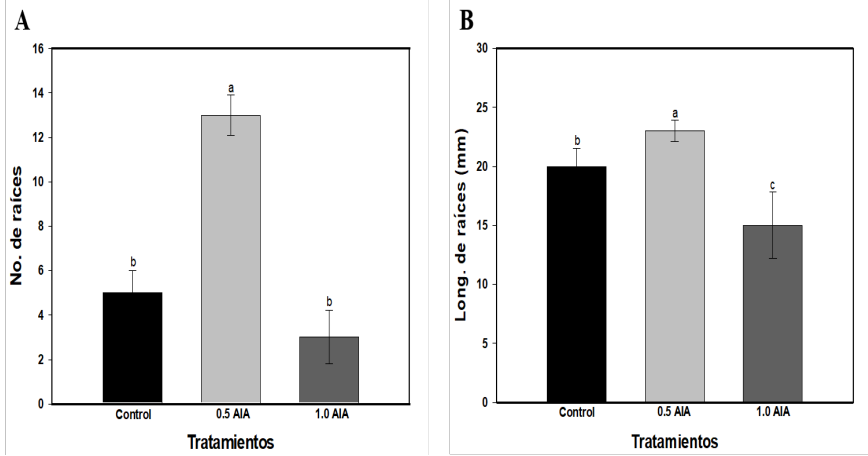

Figura 4. Efecto de las concentraciones de ácido indol acético $\left(0.5 \mathrm{mg} \mathrm{L}^{-1}\right.$ y $1.0 \mathrm{mg} \mathrm{L}^{-1}$ ) sobre la rizogénesis de brotes obtenidos de $V$. planifolia. (A) Producción media del número de raíces desarrolladas; (B) Longitud media de las raíces desarrolladas. Las barras de error representan el error estándar de las concentraciones $(n=50)$. Las medias con diferentes letras muestran diferencias significativas $(p<0.05)$.

Figure 4. Indol acetic acid concentrations effect $\left(0.5 \mathrm{mg} \mathrm{L}^{-1}\right.$ and $\left.1.0 \mathrm{mg} \mathrm{L}^{-1}\right)$ on the rhizogenesis of $V$. planifolia vitroplants. (A) Average production of developed roots; (B) Average length of developed roots. Error bars represent the standard error of the concentrations $(n=50)$. Means with different letters show significant differences $(p<0.05)$. 
una longitud promedio de $23.0 \pm 0.9 \mathrm{~mm}$. Este resultado fue estadísticamente significativo $(p<0.05)$ cuando se comparó con los otros dos tratamientos. Finalmente, el tratamiento adicionado con $1.0 \mathrm{mg} \mathrm{L}^{-1}$ de AIA registró la menor longitud radicular $(15.0 \pm 2.8 \mathrm{~mm})$, seguido del tratamiento control (20.0 $\pm 1.5 \mathrm{~mm}$ ) (Figura 4B).

\section{Preaclimatación in vitro de las plántulas}

Después de 45 días del proceso de aclimatación de las vitroplantas de $V$. planifolia, se observó que las plántulas mostraron un incremento en la altura de $18.0 \pm 1.2 \mathrm{~mm}$, de $15.0 \pm 1.0 \mathrm{~mm}$ y de $14.0 \pm 0.8 \mathrm{~mm}$ en los tratamientos TAIA0.5, control TAIA1.0, respectivamente (Figura 5A). La respuesta observada en el tratamiento TAIA0.5 fue estadísticamente diferente respecto al control $(p<0.05)$.

En cuanto a la formación de hojas nuevas (Figura 5B), se observó la producción de $1.8 \pm 0.5$ hojas por planta en los tratamientos TAIA0.5 y TAIA1.0, a diferencia del control (1.0 $\pm 0.5)$, resultando estadísticamente significativos $(p<0.05)$.
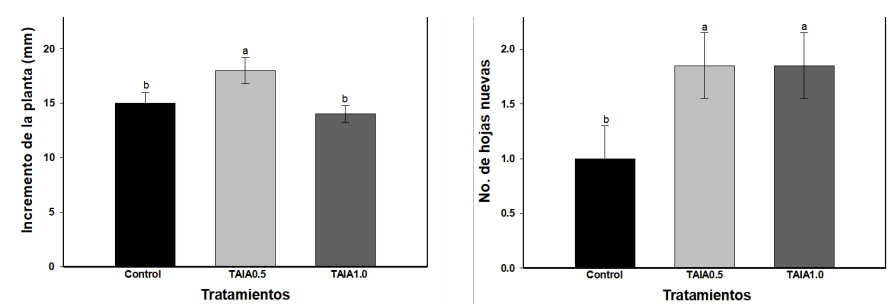

Figura 5. Efecto de las concentraciones de AIA $\left(0.5 \mathrm{mg} \mathrm{L}^{-1}\right.$ y $\left.1.0 \mathrm{mg} \mathrm{L}^{-1}\right)$ sobre la pre-aclimatación de vitroplantas de $V$. planifolia. (A) Incremento de la altura desarrollada; (B) Promedio del número de hojas desarrolladas. Las barras de error representan el error estándar de las concentraciones $(n=$ 50). Las medias con diferentes letras muestran diferencias significativas ( $p$ $<0.05)$.

Figure 5. IAA concentrations effect $\left(0.5 \mathrm{mg} \mathrm{L}^{-1}\right.$ and $\left.1.0 \mathrm{mg} \mathrm{L}^{-1}\right)$ on the pre-acclimatization of $V$. planifolia vitroplants. (A) Increase in developed height; (B) Average number of leaves developed. Error bars represent the concentrations standard error $(n=50)$. Means with different letters show significant differences $(p<0.05)$.

\section{DISCUSIÓN}

En el entorno natural, las orquídeas necesitan de la simbiosis con micorrizas tanto en la etapa de germinación de las semillas como en la etapa de desarrollo de las plántulas (Rasmussen et al., 2015). Sin embargo, a través del cultivo in vitro, la mayoría de las orquídeas pueden germinar de manera asimbiótica en un medio de cultivo estéril en el cual se les proporcionan todos los nutrientes necesarios para su desarrollo (Yang et al., 2017). En el caso de V. planifolia, sus semillas presentan las mismas limitantes que el resto de las orquídeas para poder germinar. Menchaca, 2019, indica que la germinación de las semillas depende de la etapa de maduración del fruto, por ejemplo, se ha logrado un 50\% de germinación in vitro en semillas obtenidas después de 154-200 días de polinización natural, y más de un $80 \%$ de germinación in vitro en semillas producidas después de 44 días de la polinización artificial.
En el presente estudio, la germinación se vio favorecida al colocar las semillas durante 30 días en la oscuridad, lo cual redujo el fenómeno de fotoxidación (Flores-Castaños et al., 2017), y permitió que las semillas comenzaron a germinar a los 60 días, alcanzando un máximo de germinación del $90 \%$ a los 90 días de cultivo in vitro, y sin la adición de reguladores de crecimiento. Además, el porcentaje de germinación obtenido en este estudio, también se puede atribuir al tamaño del fruto empleado $(15 \mathrm{~cm})$, considerándose como un porcentaje alto al compararse con otros estudios realizados con esta misma especie vegetal, en donde se han obtenido porcentajes de germinación del $85 \%$ al añadir otros componentes al medio de cultivo como glutamina y sulfato de adenina (Menchaca-García, 2011), y de un 90 \% cuando se utilizaron semillas inmaduras de $V$. planifolia provenientes de frutos con un tamaño máximo de $10 \mathrm{~cm}$, en condiciones similares a las evaluadas en el presente estudio (Flores-Castaños et al., 2017).

En cuanto al tiempo de germinación, éste depende del tipo de especie o híbridos de vainilla con los que se trabaje, por ejemplo se ha reportado que para V. planifolia la germinación ocurre de 100 a 130 días, para V. insignis ocurre a los 70 días, mientras que para los híbridos de Vainilla planifolia x Vanilla pompona la germinación ocurre a los 40 días (Menchaca, 2019). Los resultados de germinación observados en esta investigación concuerdan con los tiempos de germinación establecidos para V. planifolia, lo cual demuestra que el protocolo establecido fue adecuado para iniciar con la micropropagación de la vainilla.

Existen otros estudios sobre la propagación in vitro de vainilla a través del uso de yemas axilares (Lozano-Rodríguez et al., 2015), segmentos nodales (Ayele et al., 2017), esquejes y explantes nodales (Biradar et al., 2016), ápices y brotes apicales (Morwal et al., 2015; Gätjens-Boniche et al., 2018). Sin embargo, en dichos trabajos se utilizan fitohormonas sintéticas para inducir la morfogénesis de los brotes, y no existen reportes en donde se hayan utilizado sustratos naturales como el extracto de plátano, piña y agua de coco en todas las etapas del cultivo in vitro como se realizó en el presente estudio.

La adición de sustratos orgánicos naturales como el agua de coco, peptona, homogeneizado de papa, homogeneizado de plátano, jugos, y extracto de levadura puede promover el desarrollo de los brotes cultivados in vitro dado que representan una fuente de vitaminas, aminoácidos, ácidos grasos, carbohidratos, péptidos y hormonas de crecimiento (Edy \& Sucipto, 2020). En el presente estudio la adición de los extractos naturales favoreció la formación y elongación de brotes a partir de protocormos de V. planifolia, al proveerles los nutrientes necesarios para su desarrollo.

En estudios similares, se observó un incremento en el número y longitud de los brotes cuando se utilizó agua de coco en la propagación in vitro de la orquídea Vanda pumil (Maharjan et al., 2019), así como un incremento significativo en la altura de las plántulas de Phalaenopsis amboinensis cuando se utilizó una combinación de extracto de plátano y 
agua de coco (Utami \& Hariyanto, 2019). Además, la adición de jugo de piña durante la micropropagación de Dendrobium ovatum y Laelia rubescens Lindl, promovió el desarrollo de las plántulas (Thejaswini y Narasimhan, 2017; Mayo-Mosqueda et al., 2020). Los sustratos naturales favorecen la organogénesis a su vez contribuyen con la disminución de costos en el proceso de propagación in vitro (Velázquez-Kú et al., 2016). Además, se ha demostrado que los sustratos orgánicos como la piña, el plátano y el agua de coco, promueven la morfogénesis y rizogénesis dado que producen efectos similares al de las auxinas y citocininas (Menezes et al., 2016).

En la etapa de la rizogénesis de $V$. panifolia evaluada en este estudio, las raíces que se produjeron en los tratamientos con AIA mostraron vigorosidad y buena calidad, dado que se observaron de un color verde brillante y con desarrollo de velamen (Figura 2D). Estos resultados coinciden con lo reportado por Castillo-Pérez et al. (2020), quienes también lograron la producción de velamen en condiciones in vitro al propagar la orquídea Laelia anceps subsp. anceps, además de sugerir que la formación de estas estructuras en las raíces favorece el proceso de aclimatación. Por otro lado, es importante mencionar que la auxina AIA es ampliamente utilizada en procesos de micropropagación in vitro, tanto en orquídeas, como en diversas especies forestales y de importancia comercial, dado que promueve y favorece el desarrollo de raíces laterales y adventicias (Jainol y Gansau, 2016; Liao et al., 2017; Elmongy et al., 2018; Seon et al., 2018).

La longitud de las raíces es otra característica favorable que produce el uso del AIA cuando es adicionado a los medios de cultivo para la propagación in vitro de plantas. Este efecto se debe principalmente al estímulo que se lleva a cabo en la biosíntesis de proteínas y que repercute de forma positiva en el crecimiento de las raíces (Shahab et al., 2009; Boivin et al., 2016). Interesantemente, los resultados de esta investigación concuerdan con lo reportado por Maharjan et al. (2019) quienes establecieron la propagación in vitro de la orquídea epífita Vanda pumila, y encontraron que la adición de $0.5 \mathrm{mg} \mathrm{L}^{-1}$ de AIA favorece la producción y elongación de raíces. Sin embargo, observaron también que al agregar concentraciones mayores a $1.0 \mathrm{mg} \mathrm{L}^{-1}$ de AIA disminuía el desarrollo y la longitud de las vitroplantas. Además, Maharjan et al. (2020) encontraron que al adicionar $1.5 \mathrm{mg} / \mathrm{L} \mathrm{IAA}$ al medio $(1 / 2 \mathrm{M}$.S) se promovía el enraizamiento de las orquídeas Dendrobium chryseum.

Finalmente, es importante mencionar que este efecto se ha observado también en el cultivo in vitro de otras especies que no pertenecen a la familia Orchidaceae, por ejemplo, en el cultivo in vitro de Dahlia sp. se observó que las concentraciones mayores a $1 \mathrm{mg} \mathrm{L}^{-1}$ de AIA disminuyeron la producción y elongación de la raíz (Jiménez-Mariña, 2020). La concentración de AIA a emplear, dependerá del tipo de especie vegetal, y del tipo de morfogénesis que se quiera lograr durante la micropropagación. En este estudio, las concentraciones de 0.5 y $1.0 \mathrm{mg} \mathrm{L}^{-1}$ de AIA favorecieron también la etapa de pre aclimatación in vitro en otros soportes em- pleados como la tierra de jardín, al promover la elongación y maduración de las raíces.

El cultivo de tejidos sigue siendo una herramienta indispensable para la producción comercial de orquídeas, debido a su bajo costo, uniformidad, rápida propagación y alto rendimiento en poco tiempo período de tiempo. Por ejemplo, la mayoría de las orquídeas de flores cortadas (Dendrobium, Oncidium, Mokara, Aranda, Ascocenda, y Cattleya alliances) se propagan con éxito a través de la micropropagación, obteniendo hasta más de 10,000 plántulas a nivel de laboratorio listas para crecer en condiciones de invernadero (Kanchit et al., 2020). Los resultados observados en este estudio demostraron los efectos benéficos de los extractos naturales sobre la micropropagación in vitro de V. planifolia, el cual en un futuro podría desarrollarse a gran escala para producir de manera comercial esta especie vegetal en la Huasteca Potosina. Además, por tratarse de la única orquídea que produce frutos comestibles, se justifica el uso de sustratos naturales para la producción orgánica de la vainilla. Sin embargo, aún faltan realizar estudios sobre la aclimatación de las plantas en el medio ambiente natural, y determinar si esta aclimatación requerirá de la simbiosis con las micorrizas de las plantaciones naturales. Por ello, es importante la vinculación con los sectores sociales y productivos, de manera que en un futuro cercano se logre la transferencia de tecnología desarrollada a los productores de vainilla de la región Huasteca.

\section{CONCLUSIONES}

Se logró el 90\% de germinación in vitro asimbiótica para las semillas de $V$. planifolia, y la formación de protocormos. La adición de extractos naturales a los medios de cultivo favoreció la formación de brotes y de plantas in vitro, reduciendo así el uso de fitohormonas sintéticas. Los resultados mostraron que el mejor tratamiento fue el extracto de piña, en donde se observó la formación de $5.7 \pm 3.5$ brotes de 36.9 $\pm 7.3 \mathrm{~mm}$ de altura, y de $2.2 \pm 0.5$ yemas por brote. Además, se logró la formación de $13.0 \pm 1.1$ raíces por brote con la adición de $0.5 \mathrm{mg} \mathrm{L}-1$ de AIA, y la pre aclimatación de las plantas en condiciones in vitro. Estos resultados contribuyen a la creación de una nueva metodología de micropropagación in vitro para la vainilla, la cual contribuirá a reducir la presión de la sobreexplotación de $V$. planifolia, y permitirán su conservación en la Huasteca Potosina. Además, en un futuro esta herramienta biotecnológica podrá explotarse a nivel comercial para la propagación masiva de vainilla.

\section{AGRADECIMIENTOS}

Al Consejo Nacional de Ciencia y Tecnología, por el financiamiento del proyecto 269491/2016. KLTG y LJCP agradecen al CONACYT por la beca otorgada para realizar los estudios de posgrado.

\section{CONFLICTO DE INTERESES}

Los autores de este trabajo no tienen ningún conflicto de intereses. 


\section{REFERENCIAS}

AlbertoMayo-Mosqueda, A., Maceda-López, L.F., AndradeCanto, S.B., Noguera-Savelli, E., Caamal-Velázquez, H., CanoSosa, J.S., Alatorre-Cobos, F. 2020. Efficient protocol for in vitro propagation of Laelia rubescens Lindl. from asymbiotic seed germination. South African Journal of Botany. 133, 264 272. https://doi.org/10.1016/j.sajb.2020.07.030.

Ayele, Y. B., Tefera, W., Bantte, K. 2017. Enhanced Protocol Development for in vitro Multiplication and Rooting of Vanilla (Vanilla planifolia Andr.) Clone (Van. 2/05). Biotechnology Journal International, 1-11.

Biradar, V., Inamdar, A., Shamse, A., Patil, M. S. 2016. In vitro Studies on the influence of different concentrations of growth regulators on economically important orchid, Vanilla planifolia. Int. J. Curr. Microbiol. Appl. Sci, 5, 311-323.

Boivin, S., Fonouni-Farde, C., Frugier, F. 2016. How auxin and cytokinin phytohormones modulate root microbe interactions. Frontiers in plant science, 7, 1240.

Castillo-Pérez, L. J., Maldonado-Miranda, J. J., Alonso-Castro, A. J., Carranza-Álvarez, C. 2020. Efecto de 6-bencilaminopurina y nitrato de potasio sobre la micropropagación in vitro de Laelia anceps subsp. anceps (Orchidaceae). Biotecnia, 22(1), 32-38.

Chomicki, G., Bidel, L. P., Ming, F., Coiro, M., Zhang, X., Wang, Y., Baissac, Y., Jay-Allemand, C., Renner, S. S. 2015. The velamen protects photosynthetic orchid roots against UV-B damage, and a large dated phylogeny implies multiple gains and losses of this function during the Cenozoic. New Phytologist. 205: 1330-1341.

Debnath, S. C. 2009. Characteristics of strawberry plants propagated by in vitro bioreactor culture and ex vitro propagation method. Engineering in Life Sciences, 9, 239246.

Elmongy, M. S., Cao, Y., Zhou, H., Xia, Y. 2018. Root development enhanced by using Indole-3-butyric acid and naphthalene acetic acid and associated biochemical changes of in vitro azalea microshoots. Journal of Plant Growth Regulation, 37(3), 813-825.

Espinosa-Leal, C.A., Puente-Garza, C.A., García-Lara, S. 2018. In vitro plant tissue culture: means for production of biological active compounds. Planta, 248, 1-18.

Flores Castaños, O., Cuéllar Zometa, J.F., Montes de Godoy, M.E., Gámez Pastrana, M.R., González Arnao, M.T., Guevara Valencia, M., Aguilar Rivera, N. 2017. Germinación in vitro de semillas de Vanilla planifolia Jacks y comparación de métodos de micropropagación. Avances en Investigacion Agropecuaria, 21.

Gätjens-Boniche, O., Acuña-Matamoros, C.L., Montero-Carmona, W., Díaz, C., Torres, S. 2018. Propagación masiva y formación de callos protocórmicos de vainilla a partir de ápices radicales. Polibotánica. 45: 157-180.

Gaudencio-Sedano C., Manzo-Alejandro G., Reymundo-Roldán $\mathrm{H}$, Castellanos J.A. 2015. Propagación in vitro de orquídeas y otras ornamentales. Revista Mexicana De Ciencias Agrícolas. 12: 451-456.

Hernández-Hernández, J. 2011. Paquete tecnológico vainilla (Vanillaplanifolia Jackson). Establecimiento y mantenimiento (Programa Estratégico para el desarrollo Rural Sustentable de la Región Sur-Sureste: Trópico Húmedo). Tlapacoyan, Veracruz: SAGARPA-INIFAP.
Jainol, J. E., Gansau, J. A. 2016. Effect of growth regulators and explant orientation on shoot tip culture of Borneo endemic orchid, Dimorphorchis lowii. Transactions on Science and Technology, 3(2), 306-312.

Jiménez-Mariña, L. 2020. Metodología de propagación in vitro de Dahlia sp. Avances, 22(3), 406-422.

Kanchit Thammasiri, Nipawan Jitsopakul, Sasikarn Prasongsom 2020. Micropropagation of Some Orchids and the Use of Cryopreservation. En: Mérillon, J.M. \& Kodja H. (eds.). Orchids Phytochemistry, Biology and Horticulture, Series in Phytochemistry, https://doi.org/10.1007/978-3-030-112578_10-1.

Kelso-Bucio, H.A., Bâ, K.M., Sánchez-Morales, S., Reyes-López, D. 2012. Estimación in situ del Kc ini de la vainilla (Vanilla planifolia A). Agrociencia, 46, 499-506.

Liao, X., Lovett, B., Fang, W., \& St Leger, R. J. 2017. Metarhizium robertsii produces indole-3-acetic acid, which promotes root growth in Arabidopsis and enhances virulence to insects. Microbiology, 163(7), 980-991.

Lozano-Rodríguez, M.Á., Menchaca-García, R.A., Alanís-Méndez, J.L., Pech-Canché, J.M. 2015. Cultivo in vitro de yemas axilares de Vanilla planifolia Andrews con diferentes citocininas. Revista Científica Biológico-Agropecuaria Tuxpan, 4, 1153 1165.

Luna-Guevara, J.J., Ruiz-Espinosa, H., Herrera-Cabrera, E.B., Navarro-Ocaña, A., Delgado-Alvarado, A., Luna-Guevara, M.L. 2016. Variedad de microflora presente en vainilla (Vanilla planifolia Jacks. ex Andrews) relacionados con procesos de beneficiado. Agroproductividad, 9, 3-9.

Maharjan, S., Pradhan, S., Thapa, B. B., Pant, B. 2019. In vitro propagation of endangered orchid, Vanda pumila Hook. f. through protocorms culture. American Journal of Plant Sciences, 10(07), 1220.

Maharjan, S., Thakuri, L., Thapa, B., Pradhan, S., Pant, K., Joshi, G., Pant, B. (2020). In vitro propagation of the endangered orchid Dendrobium chryseum Rolfefrom protocorms culture. Nepal Journal of Science and Technology, 19(1), 39-47. https://doi.org/10.3126/njst.v19i1.29737.

Menchaca-García, R.A. 2011. Manual para la propagación de orquídeas. 1st ed. Comisión Nacional Forestal. México.

Menchaca-García, R.A. 2019. In vitro Propagation of Vanilla. En: Daphna Havkin-Frenkel, Faith C. Belanger (eds). Handbook of Vanilla. Science and Technology. Second Edition. ISBN: 978-1-119-37727-6.

Menchaca-García, R.A., Ramos, J.M., Moreno, D., Luna, M., Mata, M., Vázquez, L.M., Lozano, M.A. 2011. Germinación in vitro de híbridos de Vanilla planifolia y Vanilla pompona. Revista colombiana de biotecnología, 13, 80-84.

Menezes-Gonçalves, L., Machado, M., Ballesta, P., Mora, F., Milaneze, M., Mangolin, C. 2016. Suplementos orgánicos para el cultivo in vitro del híbrido Laeliocattleya (Orchidaceae). Idesia 34 (1), 47-54.

Morwal, G., Jadhav, S.J., Shinde, A., Mandge, N., Mandge, N. 2015. Conservation of Vanilla Planifolia by in vitro micropropagation method. In Special issue national conference "ACGT (pp. 13-14).

Murashige, T., Skoog, F. (1962). A Revised Medium for Rapid Growth and Bio Assays with Tobacco Tissue Cultures. Physiologia Plantarum. 15(3), 473-497. 
Norma Oficial Mexicana “Protección ambiental-Especies nativas de México de flora y fauna silvestres-Categorías de riesgo y especificaciones para su inclusión, exclusión o cambio-Lista de especies en riesgo". 2010. Disponible en: http://dof.gob. $\mathrm{mx} /$ nota_detalle_popup.php?codigo $=5173091$.

Rao, S. R., Ravishankar, G. A. 2002. Plant cell cultures: chemical factories of secondary metabolites. Biotechnology advances, 20, 101-153.

Rasmussen Hn, Dixon Kw, Jersáková J. Y Těšitelová T. 2015. Germinación y establecimiento de plántulas en orquídeas: un complejo de requisitos. Ann Bot 116, 391-402.

Reyes-Hernández, H., Trinidad-García, K.L., Herrera-Cabrera, B.E. 2018. Caracterización del ambiente de los vainillales y área potencial para su cultivo en la Huasteca Potosina. Biotecnia, XX, 49-57.

SAGARPA (2010). Estudio de oportunidades de mercado internacional para la vainilla mexicana. http://www.sagarpa. gob.mx/agronegocios/Documents/Estudios_promercado/ VAINILLA.pdf.

Seon, K., Kim, D., Kang, K., Sivanesan, I. 2018. Highly competent in vitro propagation of Thrixspermum japonicum (Miq.) Rchb., a rare epiphytic orchid Plant. In vitro cellular \& developmental biology, 54, 302-308.

Shahab, S., Ahmed, N., Khan, N. S. 2009. Indole acetic acid production and enhanced plant growth promotion by indigenous PSBs. African Journal of Agricultural Research, 4(11), 1312-1316.

Soto Arenas, M. (2006). La vainilla: retos y perspectivas de su cultivo. Biodiversitas 66:1-9.

Soto-Arenas, M.A. 1999. Filogeografía y recursos genéticos de las vainillas de México. Project J101, CONABIO, México.
Soto-Arenas, M.A. 2003 Vanilla. En: Pridgeon AM, Cribb PJ, Chase MW, Rasmussen FN (ed) Genera orchidacearum: Orchidoideae, Oxford University Press, EUA.

Thejaswini, R., Narasimhan, S. 2017. Undefined organic additives stimulate in vitro seed germination of Dendrobium ovatum (Willd.) Kraenzl, a medicinal orchid. Int J Pharma Med Biol Sci, 6, 29-31.

Torres-González, M.J., Aguirre-Medina, J.F., Iracheta-Donjuan, L. 2011. Germinacion de semilla y obtencion de plantulas de Vanilla planifolia Andrews en condiciones in vitro. Agroproductividad, 4, 3-9.

Utami, E.S.W., Hariyanto, S. 2020. Organic Compounds: Contents and Their Role in Improving Seed Germination and Protocorm Development in Orchids. International Journal of Agronomy, 12. https://doi.org/10.1155/2020/2795108.

Vargas Hernández, J., Gámez Velázquez, H.G. 2014. Producción de vainilla en tres sistemas de producción en la Sierra Huasteca Potosina. Instituto Nacional de Investigaciones Forestales, Agrícolas y Pecuarias. $31 \mathrm{pp}$.

Velazquez-Kú, N.V., Quijano-Ávila, J. C., Rodríguez-Ávila, N.L. 2016. Análisis de diferentes sustratos en la germinación y multiplicación in vitro de orquídeas silvestres del estado de Campeche. Revista del centro de graduados e investigación, 31, 27-31.

Yang, F. S., Sun, A. H., Zhu, J., Downing, J., Song, X. Q., Liu, H. 2017. Impacts of host trees and sowing conditions on germination success and a simple ex situ approach to generate symbiotic seedlings of a rare epiphytic orchid endemic to Hainan Island, China. The Botanical Review. 83: 74-86. 